\title{
TIMANTES Y LA PINTURA QUE HABLA EN EL MAYOR ENCANTO, AMOR
}

Frederick de Armas

Department of Romance Languages and Literatures

The University of Chicago

1115 E. 58th St., Wieboldt Hall 205

Chicago, IL 60637

fdearmas@uchicago.edu

[Anuario calderoniano (ISSN: 1888-8046), vol. extra, 1, 2013, pp. 97-113]

De todos los elementos del teatro mitológico calderoniano que estudia Margaret Greer son la poesía y la pintura, los que más se disputan y relucen en El mayor encanto, amor, primera comedia de espectáculo representada en el Palacio del Buen Retiro. Aquí, Calderón pinta con sus extremadas locuciones mientras que Cosimo Lotti habla con sus arriesgados y asombrosos escenarios la estancia de Ulises en la isla de Circe. El espectáculo calderoniano serviría para alabar al Rey Planeta en este nuevo palacio del sol ${ }^{1}$. Pero Calderón, de mane-

${ }^{1}$ Al igual que el sol que ocupaba la cuarta órbita celestial en el sistema ptolemaico, Felipe era el cuarto de su nombre y alumbra su reino y su palacio con su poderío y majestad. Se piensa que fue el embajador florentino Bernardo Monanni el que escogió el emblema del sol para Felipe IV y del girasol para Olivares (Brown y 
ra inusitada, proclama que la hechicera Circe es hija del sol y que su gran palacio es también un retiro. Los pinceles halagadores a veces se confunden con tintes más sobrios en días de fiesta y regocijo cortesano. Y son estos complejos dibujos y colores los que nos interesan. Pero, para comprenderlos, me desviaré un tanto de lecturas políticas para analizar la escritura visual de Calderón, su auto-homenaje, su homenaje a Cosimo Lotti y su meditación acerca de lo épico y lo trágico en una comedia de espectáculo ${ }^{2}$.

Y todo esto se vislumbra principalmente en el extraño papel de un personaje casi oculto en la obra, Timantes, quien sólo pronuncia una veintena de versos. Timantes representa una mnemónica onomástica, recordándole al lector o espectador culto el famoso artista de la antigüedad clásica de ese nombre, invitándole a rememorar los conceptos vitales de esta figura.

\section{TIMANTES: DIBUJO, COLOR Y PERSPECTIVA}

Timantes, tan conocido en el Renacimiento y el Barroco a través de los escritos de Plinio, Cicerón y Quintiliano, aparece repetidamente en obras de Lope de Vega, Matos Fragoso, Tirso de Molina, y Ruiz de Alarcón ${ }^{3}$; y se alude a él o aparece como personaje en al menos cuatro comedias de Calderón de la Barca ${ }^{4}$. Unos cuatro o cinco años antes de nuestra fiesta palaciega, Calderón ya había incluido una alusión a Timantes en La vida es sueño ${ }^{5}$. Tal es la vanidad de Basilio que,

Elliott, 1980, p. 200). El hecho de que el Buen Retiro se hallara al este de Madrid también apoya el mito del Rey Planeta ya que se sitúa hacia la salida del sol.

${ }^{2}$ El acercamiento político en el que se dice haber crítica del rey, del privado o de algún cortesano en la obra calderoniana comienza con la popularidad del nuevo acercamiento crítico llamado «New Historicism». Lo vemos ya en De Armas, 1986, y Greer, 1991. Tres de los más recientes trabajos sobre el asunto son los de Greer, 2000, Fernández Mosquera, 2008, y De Armas, 2011.

${ }^{3}$ Ver, por ejemplo, Lo que ha de ser (1624), La mayor victoria (1620-1622), Mirad a quién alabáis (circa 1620) y El tirano castigado (1588-1595) de Lope de Vega; Callar siempre es lo mejor de Matos Fragoso; El dueño de las estrellas de Ruiz de Alarón y Escarmientos para el cuerdo de Tirso de Molina.

${ }^{4}$ Auristela y Lisidante, Darlo todo y no dar nada, El mayor encanto, amor, y La vida es sueño.

${ }^{5}$ Se pueden encontrar numerosos paralelos entre El mayor encanto amor, y la más famosa de las obras de Calderón, tales como la presencia de personajes del mismo 
en su autoalabanza ante la corte de Polonia, el rey se describe a sí mismo como si hubiera sido representado por los más famosos pintores y escultores de la época clásica:

pues, contra el tiempo y olvido, los pinceles de Timantes, los mármoles de Lisipo, en el ámbito del orbe me aclaman el gran Basilio (vv. 607-611)

Podríamos hallar algo de ironía en esta alusión pues la más famosa pintura de Timantes tiene mucho que ver con la manipulación, uno de los grandes defectos de Basilio. El pintor sabe cómo alabar a los poderosos ${ }^{6}$.

Calderón también incluye a Timantes como personaje en una de sus obras. Cruickshank nos recuerda que Darlo todo y no dar nada se representó para el cumpleaños de la reina el 22 de diciembre de $1651^{7}$. Añade que la obra alude a la competencia entre Velázquez y otros pintores en 1627. Esto permite conjeturar que pudo existir una primera versión que correspondería con la aparición de los otros Timantes calderonianos en la década de los treinta ${ }^{8}$. En Darlo todo y no dar nada, tres pintores se afanan por crear el perfecto retrato del rey Alejandro, y entre ellos se encuentra Timantes. Ahora bien, la anécdota le debe mucho a Plinio para quien Apeles es el mejor pintor del pasado, pre-

nombre: Astrea y Clarín. Y estos personajes clarifican la importancia de la onomástica en la obra del dramaturgo - muchas figuras que parecen secundarias llevan una fuerte carga simbólica tras su nombre.

${ }^{6}$ Timantes aparece como personaje secundario en Auristela y Lisidante, obra que según Don W. Cruickshank se elaboró para una representación de 1637, la cual no se llevó a cabo. Cruickshank explica que aunque se ha dicho que la versificación parece ser de entre 1653 y 1660, pudo existir esta primera versión titulada Auristela $y$ Clariana. En la obra, Clariana es la hermana de Auristela (2009, p. 199).

7 Cruickshank 2009, p. 187.

8 «After a three-way painting competition recalling that which Velázquez won in 1627, Apeles is appointed pintor de cámara (Velázquez title), with the additional ruling that only he may paint the king in future (a concession granted to Velázquez)" (Cruickshank, 2009, p. 187). En realidad, lo que ocurrió fue una competencia entre Velázquez y tres otros pintores: Carducho, Cajés y Angelo Nardi y el tema de la pintura era la expulsión de los moriscos por Felipe III (Brown, 1986, pp. 60-61). 
sente y futuro ${ }^{9}$ pues sabe combinar el decoro, la alabanza y la omisión significativa. Pinta a Antígono, general de Alejandro Magno, de perfil para no mostrar su ojo defectuoso ${ }^{10}$. Calderón retoma la anécdota acerca de un pintor y la transforma en la competencia entre tres artistas. Melchora Romanos resume el conflicto pictórico en la obra de esta manera: "Ante la necesidad de enviar el retrato de Alejandro a su futura esposa Rojana, su consejero Efestión se adelanta y le pide a tres famosos pintores griegos Timantes, Zeuxis y Apeles, que se lo hagan» ${ }^{11}$.Y, el resultado, para Wolfenzon tiene que ver con tres maneras de pintar: la ideal en la que se ensalza al rey omitiendo el defecto; la naturalista en la que se pinta el defecto; y la perspectivista ${ }^{12}$. Calderón incluye entonces tres modos principales de representar una figura del poder.Y le da más peso a la anécdota transfiriéndola al mismo Alejandro ${ }^{13}$. O sea, que Calderón se propone entonces estudiar la representación del poder. El rey rechaza a Timantes como lisonjero e infame:

siendo

casi traición que en mi cara

9 Plinio, Natural History, 35.79.

10 Natural History, 35.90. Quintiliano elabora esta anécdota comparándola con la cara velada de Agamenón en Timantes, explicando que en la retórica y en la pintura hay cosas que no deben de representarse (The Orator's education, 2.13). «Having extolled Apelles's painting of Antigonos in profile, to hide his missing eye, he introduces Timathes's painting with the words, "So, too, in speaking, there are certain things which have to be concealed, either because they ought not to be disclosed or because they cannot be expressed as they deserve." It is not clear from the context which of these considerations Timanthes illustrates, but it could well be both» (Montagu, 1994, p. 306).

${ }^{11}$ Romanos, 2002, p. 795.

12 Wolfenson, 2007, p. 112. La fuente de esta competencia muestra la gran invención de Calderón. En el libro 35 de la Historia naturalis de Plinio, texto que, como afirma Antonio Sánchez Jiménez "constituyó la obra de cabecera de nuestros pintores del Siglo de Oro» (2011, p. 176), hallamos una serie de anécdotas sobre este pintor que se difundieron en el arte y literatura de la época, y que puede que Lope de Vega haya llevado a su máxima utilización.

13 Aunque Plinio sí elabora esta leyenda sobre Apeles, no establece una competencia entre este pintor y otros. Ni Zeuxis ni Timantes se relacionan con Alejandro. Es muy posible que Calderón concibiera la idea de la competencia leyendo en Plinio cómo Zeuxis y Parrasio se afanaron para mostrar cual de los dos imitaba con más certeza a la naturaleza. 
me mintáis. Infame ejemplo

da ese retrato a que nadie

diga a su rey sus defectos;

pues ¿cómo podrá enmendarlos

si nunca llega a saberlos? (p. 1027b)

Si la manera idealista no le place a Alejandro, tampoco acepta la naturalista de Zeuxis:

pues lo que en uno es lisonja,

es en otro atrevimiento...

Nadie le diga en su cara

al rey sus sentimientos (p. 1027b)

El rey y la obra alaban la manera perspectivista utilizada por Apeles quien representa a Alejandro de perfil:

con que la falta ni dicha

ni callada queda haciendo

que el medio rostro haga sombra

al perfil del otro medio (p. 1028a)

Ambos, Ruiz Ramón y Melchora Romanos, interpretan este momento como instructivo de lo que hace el dramaturgo, o sea encontrar un medio entre alabar y mostrar defectos ${ }^{14}$. Para mí, El mayor encanto, amor trata justamente de ese perspectivismo en el que se alaba, pero al mismo tiempo se esconden otros significados. El espectador discreto puede dibujar su propia figura de Ulises y de Circe y de la isla donde el palacio de la maga, como dijimos, se denomina el retiro.

La presencia de un personaje llamado Timantes en El mayor encanto, amor, debe de estudiarse como figura que pinta la escena y así es un tributo velado, un parangón y competencia con la escenografia de Cosimo Lotti; sirve también para reflexionar sobre los modos de pintar; sobre la representación del poder; y sobre el papel de lo trágico y heróico. El espectáculo comienza con un navío en medio de la tempestad. Timantes, como marinero en la nave de Ulises, se dedica, junto a otros, a controlar el barco. Mientras que Ulises le reza a Júpiter

${ }^{14}$ Romanos, 2002, p. 796; Ruiz Ramón, 1997, p. 25. 
y los graciosos Clarín y Lebrel añaden comicidad al momento, cada uno de los breves parlamentos de Timantes pintan o labran la escena. En el primer parlamento de este misterioso personaje nos encontramos con la mención del trinquete (p. 11), la vela triangular en la proa de la nave, que según Timantes debe alzarse durante la tormenta. Aunque los marineros se preocupan por el navío, la forma de esta vela, el triángulo, predice la llegada a Trinacria (Sicilia), llamada así por sus tres promontorios y por la general descripción de la isla como triángulo. Esta forma geométrica es también esencial para todo artista ya que tiene que ver con la teoría de la perspectiva ${ }^{15}$. También, al demandar que se alce el trinquete, puede que Timantes pida al espectador que alce los ojos y se admire al ver la nave en el mar/estanque y la isla con su monte piramidal/triangular como escenario. $O$ sea que este Timantes representa (1) al pintor que se recrea en la forma triangular y en el arte de la perspectiva; (2) al escenógrafo Cosme Lotti quien asombra al espectador con tempestad, isla y montaña; y (3) al poeta que pintará con palabras la escena y la acción.

En un dificil instante, el marinero se queja de que «monumentos de hielos / hoy serán estas ondas» (p. 11), así retóricamente labrando la tormenta para el lector o auditorio. Cuando brota la esperanza Timantes exclama: "Celajes se descubren» (p. 12). Celaje se define como: «El color que aparece, y casi continuamente se varía en las extremidades de las nubes, según las va hiriendo la luz del sol» (DRAE, p. 161).Y como bien sabemos, el espectáculo se representa para el Rey Planeta, para el Sol de España. Aquí Timantes está pintando con colores sus entornos, las nubes que lo cubren y descubren. Pintura y escultura son entonces claves para comprender los parlamentos de Timantes.

${ }^{15}$ Leon Battista Alberti, en su Arte de la pintura, asevera: «He explicado cómo, en el acto de mirar, se forma una pirámide a partir de triángulos» (1996, p. 76) y explica que el triángulo es clave para establecer la perspectiva en un lienzo. Al igual que Alberti, Leonardo de Vinci comienza su estudio de la perspectiva con esta afirmación: «La pintura se cimenta con el arte de al perspectiva, que no es sino el arte de representar lo que se ve, o sea de hacer objetos parecidos a los que contemplamos con los ojos. Semejante arte consiste en ir captando las formas y los colores de los objetos contemplados por medio de pirámides. Hablo de pirámides porque no hay objeto tan pequeño que no sea mayor a la retina, vértice de esas pirámides» (Tratado de la pintura, pp. 113-114). 
Una vez en la isla, es otra vez Timantes el que sabe pintar el paisaje, y ayuda al lector a ver el tenebroso entorno:

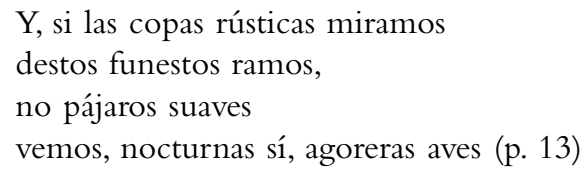

En Darlo todo y no dar nada, Timantes es el pintor de la alabanza, del elogio. Pero en este parlamento, se parece más a Zeuxis, el pintor que muestra los defectos. Trinacria, en el mundo de la mitología es isla luminosa donde habitan toda una serie de bellas criaturas, incluyendo a Dafnis, inventor de la poesía pastoril; Galatea, la bella ninfa amada por ambos Acis y Polifemo; y Butes, amante de Afrodita quien lo había salvado de las sirenas ${ }^{16}$. Pero Timantes prefiere pintarla de forma negativa, y es cierto que también se conocía como sitio de espantosos volcanes. Timantes, sin saber todavía que es refugio de la temida Circe, la pinta a como lugar nocturno y fatídico. El hipérbaton gongorino sirve para mostrar el desajuste del sitio.Y es Timantes también el que primero pronuncia la palabra clave en la obra. La isla, para él, es «todo encanto» (p. 13). Así Calderón subraya el encanto de las palabras que van a competir con el encanto de la escenografia.

Al mismo tiempo, un lector o espectador culto se preguntaría qué quiere decir Timantes con «encantos» — se trata de hechizos nefastos o asombrosas imágenes verbales que compiten con el espectáculo. Se trata entonces de la versión perspectivista de Timantes. Quintiliano la relaciona con la retórica declarando que hay veces en las que ciertas cosas deben de quedar encubiertas -o porque no deben decirse o porque no pueden ser expresadas de manera adecuada (2.13). Timantes, entonces, puede o ser el pintor de la lisonja, o el pintor que pinta defectos, o el que esconde fallas, de manera que el espectador suspicaz pueda intuirlas. En El mayor, encanto, amor, entonces vemos la triple cara de Timantes. Es pintor elogioso, ensalzando la escenografia de Lotti; es pintor que muestra los defectos de Trinacria; y es pintor perspectivista intuyendo varios tipos de encantos y revelando los va-

${ }^{16}$ Sicilia es sitio donde se alberga Dédalo después de escapar de Creta; e isla que acoge a la ninfa Aretusa, que había sido perseguida por el dios Alfeo, ahora transformada en fuente. 
rios colores de las nubes que esconden en parte al Sol de España. Es además pintor que sigue los preceptos del arte y de la retórica. Y finalmente intuimos su propósito. Cuando Ulises decide explorar la isla Timantes responde: «Todos te imitaremos / y por diversas sendas talaremos / el monte» (p. 14). El primer verbo de importancia aquí es «imitar». La pintura de Timantes y así la obra dramática de Calderón va a dibujar la figura de Ulises, va a «imitar» su figura de forma perspectivista. El segundo verbo significativo en este parlamento es «talar». Para Sebastián de Covarrubias, tala es: «La corta que se hace en el monte, derrocando los árboles desde su tronco y dejando aquel pedazo de tierra, que era monte raso" (p. 1458). La obra, entonces, va a esbozar un Ulises que desea transformar el monte, sitio lúgubre y fatídico, en un lugar luminoso y civilizado. Ulises podría entonces representar la figura del rey Felipe IV, pues muchos poetas cortesanos lo elogiaban con este nombre.Y de manera elogiosa puede que se trate de un sitio apartado transformado en el palacio y jardines del Buen Retiro.

\section{Pinturas de Circe: Juan de la Corte y Dosso Dossi}

Armado con la triaca contra los venenos de Circe, Ulises se dirige a su palacio, sabiendo por Antistes que todos sus compañeros han sido transformados por la magia de esta hechicera. Es así que confrontando a Circe logra que todos los suyos recobren forma humana. No sabemos en qué bestia fue Timantes transformado pues sólo se pregunta: «¿Qué es lo que me ha sucedido / este rato que he soñado?» (p. 25). Es entonces que Circe le pide al «retórico griego» (p. 28) que le cuente sus aventuras. En realidad, la retórica de Ulises, aunque típicamente brillante y barroca, no llega al nivel de Circe quien en una extensa relación cuenta de su vida y poderes ${ }^{17}$. Una vez que tenemos el encuentro entre Circe y Ulises, Timantes casi desaparece de

17 En un típico uso de los elementos representados por criaturas, Ulises describe su navío como delfín que vuela y neblí que corre (p. 28). Rasgos de Basilio en $\mathrm{La}$ vida es sueño aparecen en la relación de la maga. Al igual que el rey, Circe es gran conocedora de las matemáticas: «No te digo que estudié / con generoso motivo / matemáticas» (p. 30). La fiesta palaciega también utiliza el eclipse como imagen (p. 105). Y no debemos de olvidar que pintores y escultores, al igual que astrólogos y practicantes de la geometría, usaban de las matemáticas sutiles. 
la obra. O por lo menos hasta la tercera jornada. Y con ello se advierte que toda una serie de elementos retóricos dirigidos a la visión del espectador, incluyendo écfrasis dramáticas, van a configurar elementos de la fiesta. Rosa López Torrijos ya ha mostrado que una pintura de Juan de la Corte, Encuentro de Circe y Ulises, puede reflejar el momento en la primera jornada en el que Ulises llega al palacio de Circe. La galería que aparece en la pintura «nos vuelve a recordar las decoraciones arquitectónicas empleadas en el teatro» ${ }^{18}$; mientras que los tres cupidillos que revolotean arriba de Circe apuntan al amor que se desarrollar entre ella y Ulises ${ }^{19}$. Los numerosos animales que la rodean son justamente los seres humanos que Circe ha encantado. Calderón, entonces, no sólo verbaliza la escena sino que torna a uno de sus contemporáneos para pintar poéticamente a Circe en la escena. El paragone es aún más intenso ya que varias de las pinturas de Juan de la Corte se exhibían en el Buen Retiro donde se representó la obra.

Si por un lado, Calderón se muestra como íntimo rival de un pintor de la corte, por otro, muestra que su querella con Cosimo Lotti ya se ha convertido en rivalidad amistosa. Y que desea incluir en su obra elementos ecfrásticos que provienen de sus conversaciones con Cosimo. El pintor y escenógrafo florentino toma muchos de sus efectos escénicos de La liberazione di Ruggiero dall'isola d'Alcina (1625). Este ballet de Ferdinando Sarancinelli con escenografia de Guido Parigi, lo presenció Lotti en Florencia justo antes de pasar a España ${ }^{20}$. La isla de la maga Alcina se convierte en Madrid en la isla de la maga Circe, mientras que en ambos sitios el palacio de la maga será quemado y destruido al final de la obra ${ }^{21}$. La obra italiana se basa en el Orlando furioso de Ariosto, poeta que admiraba la pintura de Dosso Dossi a

18 López Torrijos, 1985, p. 230

${ }^{19}$ López Torrijos, 1985, p. 230. Este cuadro recoge toda una serie de incógnitas. Explica López Torrijos: «El lienzo que se encuentra en la colección del Banco de Urquijo de Madrid, cuya procedencia ignoramos, puede corresponder a alguna de las series de Troya hechas por el pintor y citadas anteriormente» (1985, p. 230).

20 «The last Medici festival that Lotti saw and may have thus had a strong impact on his design for El mayor encanto, amor» (Whitaker, 1997, p. 88; Blumenthal, 1986, pp. 300-303).

${ }^{21}$ Como explica Jacquot «le palais d'une magicienne est également voué a l'embrasement et a la destruction» (1964, p. 503). 
quien cita en su poema. Calderón, a través de sus conversaciones con Lotti, o simplemente utilizando su conocimiento de la pintura italiana, utiliza un famoso lienzo de Dosso Dossi para crear una écfrasis dramática de la maga ${ }^{22}$. Los siete elementos mágicos subrayados por Circe en su larga exposición ante Ulises están presentes en la pintura de Dossi ${ }^{23}$. La astrología y la quiromancia son artes que se reflejan en los extraños dibujos que Circe tiene en las manos. A la Circe de la comedia le interesa la piromancia representada por su vara que emite fuego y por un plato con elementos ardientes. La geomancia y la nigromancia se indican en la pintura con el círculo en la tierra que rodea a la maga; el augurio con las aves se indica con un pajarillo posado cerca del perro y otro muerto a sus pies; y la adivinación a través de las flores se intuye de su vestido floreado.

Al mismo tiempo, el texto pictórico contribuye al juego cortesano en que se busca la alabanza y el defecto, creando una pintura perspectivista. Hablando de astrología, dice la maga:
No te digo que del sol los veloces cursos sigo, siendo cambiante cuaderno de tornasoles y visos... aunque es estudio noble fue para mi ingenio indigno (p. 30).

Calderón elabora los elementos de Dossi, dándoles un nuevo giro. Circe no sigue el curso del sol, algo indigno para ella. Pero este sol ¿no podría representar al monarca, al Rey Planeta? ¿Cómo, entonces, interpretarían este momento en el que Circe/Olivares no quiere ser tornasol, no quiere seguir los pasos del Rey Planeta? Y recordemos que en el momento se hablaba de Olivares como girasol. Este enigma puede ser parte del perspectivismo de Calderón donde ni dice ni esconde.Y, cuando Circe se refiere al «retiro de mi palacio» (p. 34), los muy perspicaces cortesanos ¿pensarían en el palacio del Buen Retiro?

22 Según Judith Yarnall, tres pintores del dieciséis, Dosso Dossi, Pellegrino Tibaldi y Annibale Carraci se interesaron por el «mystery and power of Circe» (1994, p. 115).

${ }^{23}$ Lotti ya la había descrito en su diseño de la obra: «se ha de ver sentada en un trono de gran majestad Circe... con un bizarro y rico vestido a la persiana» (Hartzenbusch, 1918, p. 387).Y así se encuentra en la pintura, aunque en la obra Calderón, posiblemente por haberlo mencionado Lotti, lo borra. 
¿buscarían una relación entre Circe, la maga que controla a los hombres, y Olivares quien desea controlar el espacio real?

Con la piromancia, tenemos un interrogante muy diferente jes Circe, Cosimo Lotti, el mago de la fiesta quien quemará el gran palacio como grandioso espectáculo final del espectáculo? ¿O se trata simplemente de una recuperación de la historia de Dido y Eneas, como ha apuntado Alejandra Ulla Lorenzo? Nos dice que Calderón transforma el final de Polifemo y Circe creando una «Dido virgiliana que se suicida tras observar desde su atalaya la huida de Eneas» ${ }^{24}$. La pira de Dido se transforma en el incendio de todo un palacio.Y, siendo así, siendo Ulises un nuevo Eneas, ¿no recordaría al auditorio que los poetas del círculo de Felipe IV lo alaban como nuevo Ulises, como descendiente de Eneas ${ }^{25}$ ? Un público cortesano comprendería muy bien que Felipe debe de escapar las transformaciones de la maga. Al lograrlo, la obra se convierte en panegírico del rey. Calderón juega con el perspectivismo, con la idea del rey como Sol, como Eneas y como Ulises. Sus palabras adornan, recrean, asombran, sin significar explícitamente. Es una pintura muda. Puede que él sea la maga Circe con sus efectos retóricos, o puede que lo sea Lotti con su escenografía que crea maravillas, o aún el mismo Olivares. La pintura dramática invita adivinanzas y sospechas, al mismo tiempo escondiendo toda interpretación precisa ${ }^{26}$.

24 Ulla Lorenzo, 2011, p. 486.

${ }^{25}$ Marie Tanner ha mostrado que la Casa de Austria se relacionaba con Eneas y los troyanos (1993, p. 137).

${ }^{26}$ A todo esto hay que añadir otros elementos del lienzo presentes en la comedia. Circe mirando hacia lo alto, observa árboles en los que se divisan formas humanas. En la fiesta calderoniana, cuando Ulises y sus hombres primero llegan a la isla, tienen que abrirse paso a través de una selva. Ulises trata de cortar uno de los árboles, y éste responde como si fuera un nuevo Segismundo: «¡Ay, mísero de mí! ¡Ay infelice!» (El mayor encanto, amor, p. 14). Sólo cuando las verdes hojas se transforman en color sanguíneo, y una mujer arbórea reclama piedad, es que entonces Ulises comienza a creer en los encantos metamórficos de la isla. No me detengo más en esta discusión pues ya he analizado lienzo y comedia en un trabajo anterior, concluyendo: «Dosso Dossi's painting, then, contains much of the iconology necessary for the costruction of a sorceress. It could also have provided Calderón with numerous hints for the development of the action» (De Armas, 2000, p. 185). 


\title{
III. El velo de Timantes en la tercera jornadA
}

Al ver a Ulises totalmente rendido ante Circe $^{27}$, Antistes quiere despertarlo de ese sueño de amor y como por arte de magia regresa Timantes al escenario después de haber estado ausente todo la segunda jornada ${ }^{28}$. Antistes quiere dejar a los pies de Ulises las armas de Aquiles. Timantes subraya la importancia de la imagen mnemónica:

\author{
Acuérdele mudo él \\ las batallas que venció, \\ para que despertador \\ de tantos olvidos sea (p. 95)
}

Ya que las armas de Aquiles no despiertan el heroísmo de Ulises, un horrendo efecto escénico va a conmoverlo. Tras músicas lúgubres, aparece una boca que «escupe / pardas nubes de humo y fuego» (p. 97). El asombrado Ulises ve que «Va subiendo un sepulcro y en él Aquiles cubierto con un velo» (p. 97). Aquiles, pálido de faz, casi esqueleto andante, se le presenta terrible a Ulises y lo acusa de "afeminado griego» (p. 98). Le ordena que tome sus armas y salga de Tinacria, llevándolas a su sepulcro. Ante el espectro terrible del héroe de Troya ocurre la anagnórisis de Ulises. Ya reconoce su error, y se reunirá con sus compañeros para escapar de esta isla de placeres.

Timantes se limita a recalcar la transformación de Ulises: «qqué tienes?» (p. 99), pues un espectador letrado recordaría muy bien la más famosa de las pinturas del artista griego, descrita por Plinio, Cicerón, Quintiliano y muchos más. Se trata de El sacrificio de Ifigenia donde toda una serie de personajes muestran su dolor ante este penoso sacrificio que apaciguaría a Artemisa/Diana y así Agamenón podría continuar su viaje a Troya ${ }^{29}$. En la pintura de Timantes, de la cual sólo se

27 «Solo de sus gustos trata / siempre en los brazos de Circe» (El mayor encanto, amor, p. 76).

28 Timantes pinta al peripatético amante de esta manera: «... anda estos jardines, que hermosos / narcisos son de esmeralda / y, enamorados de sí, / se están mirando en las aguas» (p. 77). El dibujo retórico de Timantes es entonces multifacético, refiriéndose a la belleza vanidosa de las plantas y a los cortesanos que se admiran en los jardines de Circe y en los del Buen Retiro.

${ }^{29}$ Ya desde Homero se conocía que, según Calcas, los navíos no podrían continuar hasta que se le hiciera sacrificio a la diosa. Pero no se habla de Ifigenia. La más completa representación griega se haya en la tragedia de Eurípides, Ifigenia en Aulis. 
preservan descripciones - y una copia descubierta en las ruinas de Pompeya-, se sitúan cuatro personajes frente a un altar, entristecidos ante la muerte inminente de Ifigenia: Calcas, Ulises, Menelao, y por último, Agamenón. El dolor ya es tan insufrible en Menelao, hermano de Agamenón y tío de Ifigenia, que Timantes, según las leyendas, ya no puede pintar a alguien más atormentado. Es por eso que esconde la faz de Agamenón, padre de Ifigenia, con un velo (Plinio, 35.74; Quintiliano, 2.13). Pero hay quienes se preguntan si este velo, en vez de esconder el dolor, incluye trazas de traición y culpabilidad.

Este velo de Timantes era bien conocido en el Renacimiento. Recordemos que Giorgio Vasari, a mediados del dieciséis, había representado a Timantes dibujando El sacrificio de Ifigenia ${ }^{30}$.Y a fines del diecisiete, Tiepolo imagina un bello templo para este horrendo sacrificio. Y, como ya hemos señalado, el velo de Timantes aparece como muestra de dolor en obras tales como El dueño de las estrellas de Juan Ruiz de Alarcón y Escarmientos para el cuerdo de Tirso de Molina ${ }^{31}$. En El mayor encanto, amor, Aquiles es el que aparece con el velo pues su dolor es de gran magnitud ya que Ulises, el héroe que lo incitó a pelear en Troya, ha perdido su hombría y se deja llevar por los placeres de palacio. Recordemos que aunque Aquiles no aparece en la pintura de Timantes, es uno de los personajes claves de la historia de Ifigenia (la traen a Áulide con el pretexto de que va a casar con Aquiles). Calderón, un nuevo Timantes, no sólo nos presenta el dolor de Aquiles sino también la anagnórisis, el dolor, y arrepentimiento de Ulises, personaje presente en el lienzo. Al correr el velo de Aquiles, Ulises se da cuenta de su error. Tenemos su anagnórisis. En la pintura de Timantes,

30 "Vasari, late in life, chooses as one of the Pliny stories with which he decorates his house, the scene of Timanthes painting of Iphigenia, where the painting-within-a-painting may be a version of the altar» (Barkan, 1999, p. 109).

${ }^{31}$ La obra de Tirso, triste espectáculo del naufragio de Manuel de Sousa, descubre el cadáver de Leonor y de Diaguito y don Juan pronuncia los versos finales en los que el velo de Timantes alude al dolor:

Mármol soy, absorto quedo,

estatua en la admiración

de puro sentir no siento.

A espectáculo tan triste

eche Timantes el velo

y sirva en la compasión

de escarmientos para el cuerdo (Escarmientos para el cuerdo, p. 260). 
falta la transformación de lo trágico (el sacrificio de Ifigenia), a lo festivo (el sacrificio del ciervo). En Calderón, al correr Aquiles el velo, vemos tragedia y futura anagnórisis. En la fiesta lo trágico puede coexistir con lo cómico. La fiesta se basa en una serie de tonalidades desde la severa a la que Marcella Trambaioli llama lo entremesil ${ }^{32}$.Y entre ambos extremos tenemos a la desdichada Circe que destruye su propio palacio al no poder contener a Ulises.

Para concluir diríamos que la fiesta, entonces, tiene a un nuevo Timantes como pintor. Calderón crea una pintura que habla. Y recordemos que la estética del griego Timantes se basa en el perspectivismo, en las nociones de esconder y velar. Calderón, como nuevo Timantes, esconde algo. En esta brillante y compleja obra, el espectador, sea un cortesano crítico de Olivares o un rey que desea ser alabado, escucha lo que desea. Es obra abierta, compleja, donde una visión universal de los valores del héroe épico coincide con tópicos del momento. El color de la palabra crea un encanto que cautiva al espectador como si fuera un sujeto de Circe. Su isla, su palacio, esconde muchos enigmas que no pueden descifrarse en medio de tanta magia. Habría que partir del palacio, del retiro de Circe, del palacio del Buen Retiro para preguntarse si es un sitio de ensueños donde los reyes pueden vivir adormecidos y subyugados ${ }^{33}$. Nada se dice; todo se encubre ya que un cuestionable decoro, el defecto escondido, es la marca de Timantes.

${ }^{32}$ Ver Trambaioli, 1998a, 1998b.

33 En su edición española, Brown y Elliott van mucho mas allá en sus percepciones de El mayor encanto, amor como obra con tonos políticos: «Pero Calderón transformó al gigante de Lotti en esclavo de Circe, dando ocasión con ello a una serie de equivalencias. La del palacio de Circe y el Buen Retiro estaba clara. También la de Ulises y un Felipe IV de quien se esperaba que suspendiera sus placeres para capitanear a su pueblo en la guerra. ¿Y acaso Circe no podía ser el conde-duque, que durante demasiado tiempo había tenido esclavizado al rey?» (Brown y Elliott, 2003, p. 207). 


\section{BiBLIOGRAFÍA}

Alberti, L. B., De la pintura, ed. J. V. Field, México, Mathema, 1996.

Barkan, L., Unearthing the Past. Archeology and Aesthetics in the Making of Renaissance Culture, New Haven / London, Yale University Press, 1999.

Blumenthal, A. R., Giulio Parigi's Stage Designs: Florence and the Early Baroque Spectacle, New York, Garland Publishing, 1986.

Brown, J., Velázquez, New Haven, Yale University Press, 1986.

Brown, J. y J. H. Elliott, A Palace for a King: The Buen Retiro and the Court of Philip IV, New Haven, Yale University Press, 1980.

- Un palacio para el rey. El Buen Retiro y la corte de Felipe IV, ed. revisada y ampliada, Madrid, Taurus, 2003.

Calderón de la Barca, P., Comedias. II. Segunda parte de comedias, ed. S. Fernández Mosquera, Madrid, Biblioteca Castro, 2007.

- Darlo todo y no dar nada. Obras completas, vol. 1, Dramas, ed. Á. Valbuena Briones, Madrid, Aguilar, 1969, pp. 1019-1067.

- El mayor encanto, amor. Comedias. II. Segunda parte de comedias, ed. S. Fernández Mosquera, Madrid, Biblioteca Castro, 2007, pp. 9-106.

- La vida es sueño, ed. C. Morón, Madrid, Cátedra, 1990.

Covarrubias Horozco, S. de, Tesoro de la lengua Castellana o Española, ed. I. Arellano y R. Zafra, Madrid / Frankfurt, Iberoamericana / Vervuert, 2006.

Cruickshank, D. W., Don Pedro Calderón de la Barca, Cambridge, Cambridge University Press, 2009.

De Armas, F. A., The Return of Astraea: An Astral-Imperial Myth in Calderón, Lexington, University of Kentucky Press, 1986.

- «The Enchantments of Circe: Dosso Dossi, and Calderón's El mayor encanto, amon, en Calderón. Protagonista eminente del barroco europeo, ed. K. Reichenberger, Kassel, Edition Reichenberger, 2000, pp. 175-192.

- "Claves políticas en las comedias de Calderón: el caso de El mayor encanto amon, Anuario calderoniano, 4, 2011, pp. 117-144.

Diccionario de la lengua española de la Real Academia Española (1831).

Fernández Mosquera, S., «El significado de las primeras fiestas cortesanas de Calderón», en Calderón y el pensamiento ideológico y cultural de su época: XIV Coloquio Anglogermano sobre Calderón, Heidelberg, 24-28 de julio de 2005, ed. M. Tietz y G. Arnscheidt, Stuttgart, Steiner, 2008, pp. 209-232.

— «Introducción», P. Calderón de la Barca, Comedias. II. Segunda Parte de Comedias, Madrid, Biblioteca Castro, 2007.

FISCHER, S., "Calderón's El mayor encanto, amor and the Mode of Romance», en Studies in Honor of Everett W. Hesse, ed. W. McCrary y J. A. Madrigal, Lincoln, Nebraska, Society of Spanish and Spanish-American Studies, 1981, pp. 99-112. 
Greer, M. R., The Play of Power: Mythological Court Dramas of Calderón de la Barca, Princeton, Princeton University Press, 1991.

- «El poder en juego: El mayor encanto, amon», en Estudios sobre Calderón, ed. J. Aparicio Maydeu, Madrid, Istmo, 2000, vol. 2, pp. 649-692.

Hartzenbusch, J. E. (ed.), Comedias de don Pedro Calderón de la Barca, Biblioteca de Autores Españoles, vol. 7, Madrid, Sucesores de Hernando, 1918. JACQUOT, J., «Les types de lieu théâtral et leurs transformations de la fin du Moyen Age au milieu du Xvire siècle», Le lieu théâtral à la Renaissance, Paris, CNRS, 1964, pp. 473-509.

López Torrijos, R., La mitología en la pintura española del Siglo de Oro, Madrid, Cátedra, 1985.

Montagu, J., "Interpretations of Timanthes's Sacrifice of Iphigenia», en Sight $\mathcal{E}$ Insight: Essays on art and culture in honour of E. H. Gombrich at 85, ed. J. Onians, London, Phaidon, 1994, pp. 305-325.

Pliny, Natural History, Libros XXXIII-XXXV, trad. H. Rackham, Loeb Classical Library \#394, Cambridge, Harvard University Press, 1995.

Quintillian, The Orator's Education, Books I and II, ed. y trad. D. A. Russell, Loeb Classical Library \#124, Cambridge, Harvard University Press, 2001.

Romanos, M., "Alejandro Magno y la ejemplaridad de la historia antigua en el teatro de Calderón", en Calderón 2000: Homenaje a Kurt Reichenberger en sus 80 cumpleaños, ed. I. Arellano, Kassel, Reichenberger, 2002, vol. 1, pp. 789-801.

Ruiz Ramón, F., Paradigmas del teatro clásico español, Madrid, Cátedra, 1997.

SÁNCHEZ Jiménez, A., El pincel y el Fénix: pintura y literatura en la obra de Lope de Vega Carpio, Madrid / Frankfurt, Iberoamericana / Vervuert, 2011.

Tanner, M., The Last Descendants of Aeneas. The Hapsburgs and the Mythic Image of the Emperor, New Haven, Yale University Press, 1993.

Tirso De Molina, Escarmientos para el cuerdo. Obras dramáticas completas, ed. B. de los Ríos, Madrid, Aguilar, 1958, vol. 3.

Trambaioli, M., «La faceta lúdica de la mitología en las fiestas cortesanas de Calderón», en Texto e imagen en Calderón. Undécimo Coloquio Anglogermano sobre Calderón, St. Andrews, Escocia, 17-20 de Julio de 1996, ed. M. Tietz, Stuttgart, Franz Steiner Verlag, 1998a, pp. 254-271.

— «Tonalidades entremesiles en el teatro palaciego de Calderón», Atti del 1 Seminario Internazionalde sui Secoli d'Oro (Firenze, 8-12 settembre 1997), Firenze, Alinea Editrice, 1998b, pp. 287-303.

Ulla Lorenzo, A., "Sobre la reescritura de los finales en las comedias de Calderón: Polifemo y Circe (1630) y El mayor encanto, amor $(1635,1668) »$, en Compostella aurea. Actas del VIII Congreso del Siglo de Oro (AISO), ed. A. Azaustre Galiana y S. Fernández Mosquera, Santiago de Compostela, Universidad de Santiago de Compostela, 2011, vol. 2, pp. 485-496. 
Vinci, L. da, Tratado de la pintura, ed. M. Abril, Madrid, Aguilar, 1964, 4a edición.

Whitaker, S. B., «Calderón's El mayor encanto, amor in Performance: Eyewitness Accounts by Two Florentine Diplomants», en The Calderonian Stage: Body and Soul, ed. M. Delgado Morales, Lewisburg, Bucknell University Press, 1997, pp. 81-104.

Wolfenzon, C., «Calderón, Velázquez y el arte de develar las formas de construcción de la realidad», Bulletin of the Comediantes, 59.1, 2007, pp. 109130.

Yarnall, J., Transformations of Circe: The History of the Enchantress, Urbana / Chicago, University of Illinois Press, 1994. 